\title{
Carcinogenic nitrosamines in traditional beer as the cause of oesophageal squamous cell carcinoma in black South Africans
}

C Isaacson, ${ }^{1,2}$ MB BCh, PhD (Med) (deceased); P Mothobi, ${ }^{3}$ BSc, MSc (Pharmaceutics); M Hale, ${ }^{1,2}$ MB ChB, LRCP\&S, FCPath; L K Tomar, ${ }^{3}$ BSc, MSc, PhD; C Tyagi, ${ }^{3}$ BSc, MSc, PhD; P Kumar, ${ }^{3}$ BPharm, MPharm; Y E Choonara, ${ }^{3}$ BPharm, MPharm, PhD; M Altini, ${ }^{1}$ BDS, MDent, DSc; V Pillay, ${ }^{3}$ BPharm, MPharm, $\mathrm{PhD}$

\author{
${ }^{1}$ Department of Anatomical Pathology, Faculty of Health Sciences, University of the Witwatersrand, Johannesburg, South Africa \\ ${ }^{2}$ National Health Laboratory Service, Johannesburg, South Africa \\ ${ }^{3}$ Wits Advanced Drug Delivery Platform Research Unit, Department of Pharmacy and Pharmacology, School of Therapeutic Sciences, \\ Faculty of Health Sciences, University of the Witwatersand, Johannesburg, South Africa
}

Corresponding author: V Pillay (viness.pillay@wits.ac.za)

\begin{abstract}
Background. Before the 1930s, squamous cell carcinoma (SCC) of the oesophagus was almost unknown among black South Africans. From the 1930s the annual frequency rose. A dietary cause was sought, the staple diet of black people having changed from sorghum to maize (corn), with traditional beer being brewed from maize. Carcinogenic N-nitrosamines in traditional beer were suggested as a cause of SCC of the oesophagus, with Fusarium moniliforme, a corn saprophyte, thought to play a role.

Objectives. To confirm the presence of $\mathrm{N}$-nitrosamines in traditional beer and demonstrate a mechanism for the oncogenesis of oesophageal carcinoma.

Methods. Analysis by high-performance liquid chromatography was conducted for the identification of nitrosamines in traditional beer samples, and molecular docking studies were employed to predict the affinity between N-nitrosamines and the S100A2 protein.

Results. Carcinogenic N-nitrosamines were identified in all six samples of traditional beer examined ( $N=18$ analyses), and docking studies confirmed a high affinity of the nitrosamine N-nitrosopyrrolidone with the S100A2 protein. This may result in the altered expression of the S100A2 protein, leading to tumour progression and prognosis.

Conclusion. It is suggested that carcinogenic N-nitrosamines in traditional beer are a major factor in the causation of SCC of the oesophagus in black South Africans. N-nitrosamines have been shown to produce cancer experimentally, but there has not been conclusive epidemiological evidence that $\mathrm{N}$-nitrosamines are carcinogenic to humans. This study is the first to demonstrate the potential link between $\mathrm{N}$-nitrosamines and a human tumour.
\end{abstract}

S Afr Med J 2015;105(8):656-658. DOI:10.7196/SAMJnew.7935

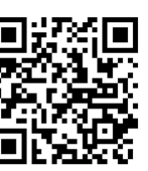

Squamous cell carcinoma (SCC) of the oesophagus dominates the oesophageal cancer landscape in the Middle East, Africa, Asia and parts of Europe. The global incidence rates are highest in Northern China, South Africa (SA), Turkey and Iran. In the USA, black people have a five times higher incidence than whites. ${ }^{[1]}$

SCC of the oesophagus is common among black South Africans. ${ }^{[2]}$ From 1912 to 1927 , no case of SCC of the oesophagus was recorded in the files of the South African Institute for Medical Research. ${ }^{[2]}$ The tumour started to appear in small numbers in the 1930 s, reached a peak in the 1980 s and then started to decline, so that today the numbers are one-fifth of what they were at their highest. Based on the premise that a carcinogen exerts its tumorigenic effect for approximately 30 - 40 years for a tumour to manifest, a cause was sought dating from 30 years prior to the 1930s when the tumour first appeared. Among various potential causes considered, a dietary change emerged as a potentially significant factor. ${ }^{[2]}$

A major dietary alteration at the turn of the 20th century was the change of the staple diet of black Africans from sorghum to maize. This is considered a pivotal factor in the causation of SCC of the oesophagus. ${ }^{[3]}$ The probable reason for the change was that agricultural production of maize was more profitable, and although sorghum can grow in harsh environments, the yields are lower. Of note, sorghum is the staple diet of Nigeria, where SCC of the oesophagus is infrequent. ${ }^{[4]} \mathrm{SA}$, where maize is the staple diet, has a high incidence of SCC of the oesophagus. ${ }^{[3]}$
The fungus Fusarium moniliforme grows freely on maize, but poorly on sorghum. ${ }^{[5]}$ Mouldy cereals containing the fungus F. moniliforme have been suggested to play a significant role in the causation of oesophageal cancer. ${ }^{[6]}$ Fusarium produces a toxin, fumonisin, which reduces nitrates to nitrites and in the presence of secondary amines synthesises nitrosamines. Nitrosamines are the suggested carcinogens. ${ }^{[7]}$

Traditional beer was produced by fermenting maize (often with sorghum added) in iron containers that, as they rusted with the passage of time, released large quantities of iron into the beer, which was deposited in tissues as haemosiderin. ${ }^{[8]} \mathrm{A}$ postmortem series demonstrated that the level of iron overload, reflected in the amount of haemosiderin in the tissues in males and females dying of natural causes, correlated with traditional beer consumption. ${ }^{\left[{ }^{[9}\right.}$ A subsequent postmortem study of patients dying of oesophageal carcinoma showed much higher tissue haemosiderin levels, indicating that they had consumed considerably more traditional beer than control patients dying of other illnesses. This suggested the possibility of carcinogens in traditional beer. Haemosiderin levels can therefore be used as a surrogate marker of traditional beer consumption. It has been proposed that the fall in the incidence of SCC of the oesophagus among black South Africans reflects diminished consumption of traditional beer. ${ }^{[8,9]}$

The current study focused on highlighting the number of cases of SCC of the oesophagus from 1912 to 2010, as well as confirming the presence of carcinogenic $\mathrm{N}$-nitrosamines via high-performance liquid chromatography (HPLC) and the interaction of N-nitrosamines 
with S100A2 protein to determine the actual mechanisms of this interaction using molecular docking studies. The S100A2 protein is an endogenous protein that is a normal component of the oesophageal wall, and its altered expression has been associated with 'tumor progression and prognosis. ${ }^{\text {'[10] }}$

We proposed that the carcinogenic property of $\mathrm{N}$-nitrosamines in the oesophagus may alter the expression of the S100A2 protein by changing its $3 \mathrm{D}$ conformation and hence its normal functioning. ${ }^{[11,12]}$ To date, however, there have been no robust studies to quantitatively prove this interaction.

\section{Methods}

\section{Study design and data collection}

At the turn of the 20th century, pathology services at most SA public hospitals were provided by the South African Institute for Medical Research (SAIMR). In 1951, the SAIMR established the Department of Anatomical Pathology at Baragwanath Hospital, Johannesburg. Subsequently the National Health Laboratory Service administered the public sector pathological services in SA. The data reported in this study were obtained retrospectively from the records of the Department of Anatomical Pathology situated at Johannesburg and Chris Hani Baragwanath hospitals to assess the frequency of SCC of the oesophagus in black South Africans from 1912 to 2010

\section{Detection of N-nitrosamines in traditional beer}

Six samples of traditional beer were obtained from four traditional brewers (brewers A, B, $\mathrm{C}$ and $\mathrm{D}$ ) in rural areas in the proximity of Kimberley, a town in the Northern Cape Province of SA. Three specimens were obtained from brewer $A$ and one each was obtained from brewers B, C and D. For statistical robustness, each of the six samples was analysed in triplicate $(N=18)$ by HPLC (Waters Model 1525 Breeze, USA) using a fluorescence detector (Acquity UPLC Fluorescence FLR, USA) with excitation and emission wavelengths at $350 \mathrm{~nm}$ and $530 \mathrm{~nm}$, respectively.

\section{Reference standard and sample preparation}

A nitrosamine mix stock solution containing seven N-nitrosamines, namely N-nitroso-nmethylethylamine (NMEA), N-nitrosodi-nbutylamine (NDBA), N-nitrosodi-n-propylamine (NDPA), N-nitrosodiethylamine (NDEA), N-nitrosodimethylamine (NDMA), $\mathrm{N}$-nitrosopiperidine (NPIP) and N-nitrosopyrrolidine (NPYR), was purchased from Sigma Aldrich, Germany. Individual reference standards of NDBA, NDEA, NDMA and NPYR, known oesophageal carcinogens, were also purchased from Sigma Aldrich. A mix

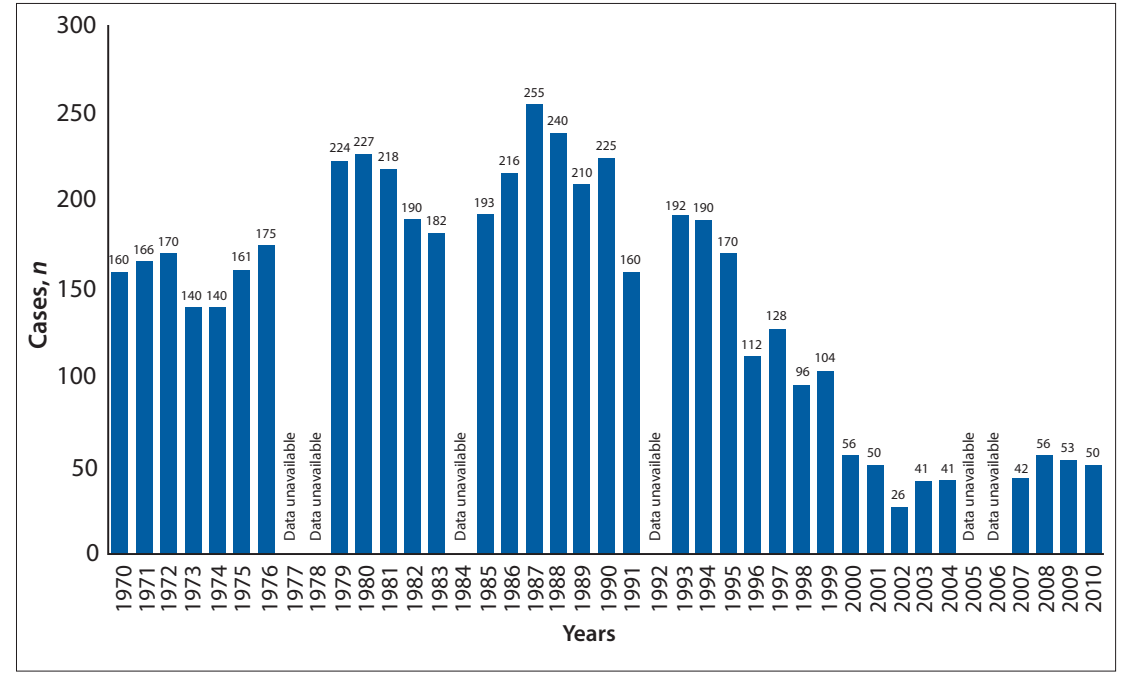

Fig. 1. Annual number of cases of SCC of the oesophagus, $1970-2010$.

Table 1. Potentially carcinogenic nitrosamines identified in traditionally brewed beer samples

\begin{tabular}{|c|c|c|c|c|c|}
\hline \multirow[b]{2}{*}{ Samples* } & \multicolumn{5}{|c|}{ Nitrosamines } \\
\hline & NDMA & NDEA & NDPA & NPYR & NDPhA \\
\hline Brewer A1 & + & + & - & + & - \\
\hline Brewer A2 & - & - & - & + & - \\
\hline Brewer A3 & + & - & - & - & - \\
\hline Brewer B & + & - & - & - & - \\
\hline Brewer C & + & + & - & - & - \\
\hline Brewer D & + & - & - & + & - \\
\hline
\end{tabular}

standard solution containing $0.1 \mathrm{mg}$ of each of the seven $\mathrm{N}$-nitrosamines was prepared from the stock according to the method established by Wang et al. ${ }^{[13]}$ Individual reference standards of NDBA, NDEA, NDMA and NPYR were also prepared separately for identification purposes. ${ }^{[11]}$

\section{Molecular docking studies}

Quantitative molecular docking studies were performed to determine the degree of $\mathrm{N}$-nitosamine-S100A2 interaction and the affinity of the N-nitrosamines for theS100A2 protein. All computations were completed online at www.dockingserver.com, hosted by Virtua Drug Ltd, Hungary. Gasteiger partial charges were added to the ligand atoms. Non-polar hydrogen atoms were merged, and rotatable bonds were defined. Docking calculations were carried out on the NPYR-S100A2 model using the Lamarckian genetic algorithm. Each docking experiment was derived from ten different runs that were set to terminate after a maximum of 250000 energy evaluations. The population size was set to 150 . During the search, a translational step of $0.2 \AA$, and quaternion and torsion steps of 5 were applied. ${ }^{[14]}$

\section{Results}

An analysis of the results presented in Fig. 1 shows a dramatic increase in the frequency of SCC of the oesophagus from the 1970s to the 1990s. The tumour started to manifest in the 1930s with an average of four cases per annum, increasing rapidly to nine cases per annum in $1940-1949$ and 167 cases per annum in 1970 - 1979. Fig. 1 depicts the rising frequency, showing the numbers from 1970 to 2010 in greater detail. The frequency reached a peak of 255 in 1987. The numbers then started to decline, and for the past 10 years have averaged 41 cases per annum.

\section{Results of HPLC analysis}

The traditional beer specimens were analysed for the presence of potentially carcinogenic $\mathrm{N}$-nitrosamines by HPLC (Table 1). The chromatogram of the reference standard displayed the elution of NDMA, NPYR, NDEA and NPIP at a concentration of $0.1 \mathrm{mg} / \mathrm{mL}$. All $20 \mathrm{~mL}$ aliquots of the traditional beer samples revealed the presence of the experimental carcinogens NDMA, NDEA and/or NPYR. The HPLC chromatograms revealed the clear separation of five of the nitrosamines at their respective retention times. 


\section{Molecular docking of $\mathrm{N}$-nitrosamines with the S100A2 protein}

The molecular stability of a ligand/protein complex was determined by calculating the final binding energy on the complex, where a negative energy of binding confirms that the complex is stable and its formation is favoured. These NPYR/S100A2 complexes represented a negative established free energy of binding $(-4.92 \mathrm{kcal} / \mathrm{mol})$ resulting from the various intermolecular energies. The binding mode of NPYR and the S100A2 protein had an established inhibition constant with a concentration value of $247.28 \mu \mathrm{M}$ and a large interaction surface at a frequency of $100 \%$. These results confirm the high affinity and interaction of NPYR with the S100A2 protein.

\section{Molecular docking analysis of the N-nitrosopyrrolidine-S100A2 interaction complex}

The binding mode achieved in the molecular docking studies is presented in Fig. 2. An established inhibition constant and a large interaction surface with a frequency of $100 \%$ occurrence was displayed in accordance with the modelling parameters. This confirmed the high affinity of NPYR towards the S100A2 protein. Furthermore, it was predicted that owing to the high affinity of the molecular complex for S100A2, NPYR is able to alter the expression of S100A2. This leads to failure of the functional complex and its complementary derivatives, cell differentiation and node metastasis, and cell cycle progression, and eventually induces carcinogenesis. ${ }^{[10,11]}$

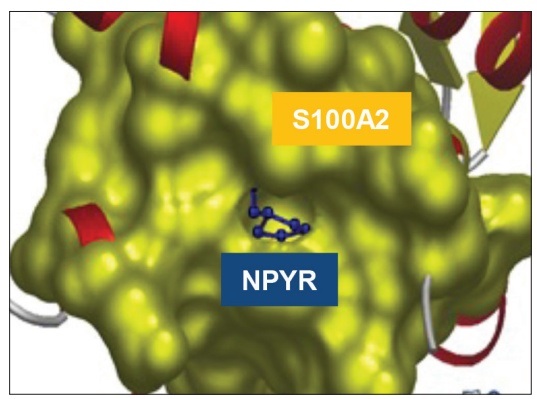

Fig. 2. The best conformational binding mode between NPYR (blue) and S100A2 (yellow).

\section{Discussion}

From 1912 to 1927, not a single case of SCC of the oesophagus was documented in the files of the SAIMR. ${ }^{[2]}$ The tumour started to appear in small numbers in the 1930s, increasing annually to reach a peak of 255 cases in 1987 . The frequency then started to decline to the current average of 40 per annum.

The recent fall in the number of SCCs of the oesophagus is probably a result of diminished consumption of traditional beer. In the apartheid era, the black people of SA were not permitted by statute (the Natives (Urban Areas)
Act No. 21 of 1923) to buy regular liquor, and were permitted only to drink traditional beer. It is hypothesised that SA blacks now have free access to regular liquor and are drinking less traditional beer. The tumour has fallen in frequency to one-fifth of its highest level, without any input from the medical profession or the pharmaceutical industry.

The premise of the current study is that carcinogenic nitrosamines in fungal-infected traditional maize-brewed beer are the cause of SCC of the oesophagus. Segal et al. ${ }^{[15]}$ concur with this view. The hypothesis receives support from studies in HPLC and molecular docking. It was possible to separate all seven $\mathrm{N}$-nitrosamines found in the $\mathrm{N}$-nitrosamine mix standard. ${ }^{[13]}$ Based on a comparison with the N-nitrosamine mix standards, NDMA, NPYR and NDEA, all carcinogenic nitrosamines, were identified in the traditional beer samples. The critical interaction between NPYR and the S100A2 protein demonstrates the role these nitrosamines may play in the development of SCC of the oesophagus. Molecular docking analysis confirms the potential mechanism of $\mathrm{N}$-nitrosamines in the pathogenesis of oesophageal SCC. Nitrosamines may act on the S100A2 protein, causing conformational changes in the protein that alter its normal functioning. ${ }^{[10,11]}$

The current research is the culmination of a sequence of earlier studies. In 1950 Walker and Arvidsson ${ }^{[16]}$ demonstrated that there was excess iron in the diet from iron utensils used during the preparation of traditional beer. In 1962, Bothwell and Isaacson ${ }^{[9]}$ quantitatively assessed the postmortem haemosiderin content of organs of patients dying of natural causes, and Isaacson et al ${ }^{[8]}$ showed in 1985 that the organs of patients dying of SCC of the oesophagus contained considerably more haemosiderin, as a marker of traditional beer consumption, than control patients, indicating that they had consumed more traditional beer than the controls.

In 2005 Isaacson $^{[3]}$ postulated that the change of the staple diet from sorghum to maize at the turn of the 20th century played a significant role in the causation of SCC of the oesophagus. In the current study, HPLC identified carcinogenic $\mathrm{N}$-nitrosamines in traditional beer, while molecular docking elucidated the probable mechanism of oesophageal carcinogenesis by $\mathrm{N}$-nitrosamines.

The data presented in this article support the hypothesis presented by Isaacson ${ }^{[3]}$ in 2005, and demonstrate a lag period of approximately 30 years between the change in the staple diet and the increase in the incidence of SCC, supporting a dietary cause. ${ }^{[3]}$ Furthermore, the current decrease in incidence may reflect a reduced consumption of traditional beer in favour of commercially brewed products.

$\mathrm{N}$-nitrosamines have been shown experimentally to produce cancer, but there has been no conclusive epidemiological evidence to show that they are carcinogenic to humans. ${ }^{[17]}$ In October 2009, the US Environmental Protection Agency listed five nitrosamines as 'probably carcinogenic to humans': NDEA, NDMA, NDPA, NPYR and $\mathrm{N}$-nitrosodiphenylamine (NDPhA). ${ }^{[18}$ Our study has identified carcinogenic $\mathrm{N}$-nitrosamines in six out of six beer samples, and is the first to demonstrate carcinogenic $\mathrm{N}$-nitrosamines in traditional beer. It is suggested that these $\mathrm{N}$-nitrosamines play a major role in the causation of SCC of the oesophagus.

\section{Conclusion}

This study may be the first to demonstrate a link between carcinogenic $\mathrm{N}$-nitrosamines and a human tumour.

Acknowledgements. This work was pioneered by Prof. Charles Isaacson (1929 - 2014), and is a tribute to his contributions as a leading researcher in the field of anatomical pathology.

\section{References}

1. Lawrence L, Charles RT. Squamous cell cancer of the oesophagus: The forgotten one. Gastrointest Cancer Res 2011;4(1):22-23.

. Isaacson C. Pathology of a black African population. In: Berry CL, Grundman E, Kirsten WH, eds. Current Topics in Pathology. Berlin: Springer Verlag, 1982.

. Isaacson $C$ The change of the staple diet of black South Africans from Isaacson C. The change of the staple diet of black South Africans from crin to [http.//dx doi.0rg/10.1016/jmehy 200409.019]

4. Pindiga HU, Akang EE, Thomas JO, et al. Carcinoma of the oesophagus in Ibadan. East Afr Med J 1997;74(5):307-310.

5. Moretti A, Bennett GA, Logrieco A, et al. Fertility of Fusarium monilliforme from maize and sorghum related to fumonisi production in Italy. Mycopathologia 1995;131(1):25-29. [http:// dx.doi.org/10.1007/BF01103900]

6. Marasas WFO, van Rensburg SJ, Mirocha CJ. Incidence of Fusarium species and the mycotoxins deoxynivalenol and zearalenone in corn produced in oesophageal cancer areas in Transkei. Agric Food Chem 1979;27(5):1108-1112. [http://dx.doi.org/10.1021/j60225a013]

Melhado RE, Alderson D, Tucker $O$. The changing face of oesophageal cancer Cancers 2010;2(3):1379-1404 [http dx.doi.org/10.3390/cancers2031379]

8. Isaacson C, Bothwell TH, MacPhail AP, et al. The iron status of urban black subjects with carcinoma of the oesophagus. S Af Med J 1985;67(15):591-593. 9. Bothwell TH, Isaacson C. Siderosis in the Bantu: A comparison
of incidence in males and females. BMJ 1962;1(5277):522-524. of incidence in males and females. BMJ 1962;1(5277):522-524.
http://www.jstor.org/stable/20356782 (accessed 19 June 2015).

10. Chen $\mathrm{H}, \mathrm{Xu} \mathrm{C}$, Jin Q, et al. S100 protein family in human cancer. Am J Cancer Res 2014;4(2):89-115.

11. Haneef M, Lohani M, Dhasmana A, et al. Molecular docking of known carcinogen 4-(methyl-nitrosamino)-1-(3-pyridyl)1-butanone (NNK) with cyclin dependent kinases toward its potential role in cell cycle perturbation. Bioinformation 2014:10(8):526-532. [http://dx.doi.org/10.6026/97320630010526]

12. Morales P, Arranz N, Haza AI. Apoptosis induced by n-nitrosamines in two cancer cell lines. Journal of Environment Protection a (htp://dx.doi. Po. 10.4236/jep.2010.13037]

3. Wang $\mathrm{Z}, \mathrm{Xu} \mathrm{H}, \mathrm{Fu} \mathrm{C}$. Sensitive fluorescence detection of some nitrosamines by precolumn derivatization with dansyl chloride and high performance liquid chromatography. J Chromatogr 1992;589(12):349-352. [http://dx.doi.org/10.1016/0021-9673(92)80044-U]

14. Kumar P, Choonara YE, Pillay V. In silico affinity profiling of neuroactive polyphenols for post-traumatic calpain inactivation: A molecular docking and atomistic simulatio sensitivity analysis. Molecules 2015;20(1):135-168. [http:// dx.doi.org/10.3390/molecules20010135

15. Segal I, Reinach SG, de Beer M. Factors associated with oesophagea cancer in Soweto, South Africa. Br J Cancer 1988;58(5):681-686. 6. Walker ARP, Arvidsson UB. Iron overload in the South African Bantu. Trans R Soc Trop Med Hyg 1953;47(6):536-548.

17. Jakszyn P, Gonzalex CA. Nitrosamine and related food intake and gastric and oesophageal cancer risk: A systematic review of the epidemiological evidence. World J Gastroenterol 2006;12(27):4296-

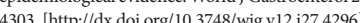
8. Selin NE. Environmental Guidelines and Regulations 18. Selin NE. Environmental Guidelines and Regulations
for Nitrosamines: A Policy Summary. Cambridge, MA: Massachusetts Institute of Technology, 2011.

Accepted 4 April 2015. 